\title{
Ambientes de Aprendizagem Cooperativa Apoiada pelo Computador e sua Epistemologia
}

\author{
Julio Alberto Nitzke * \\ Mára Lúcia Fernandes Carneiro \\ Sérgio Roberto Kieling Franco
}

\begin{abstract}
Resumo: Um ambiente de Aprendizagem Cooperativa Apoiada pelo Computador (ACAC) pode ser um elemento muito importante no processo de aprendizagem em qualquer domínio, quando a abordagem epistemológica que orientou sua criação e desenvolvimento esteja em consonância com a teoria que fundamenta a prática didática do professor. Assim, a efetividade destes ambientes só pode ser avaliada frente a um determinado paradigma de aprendizagem. Neste trabalho, foram avaliados ambientes de ACAC sob a ótica de uma abordagem sócio-construtivista da Teoria da Epistemologia Genética, de Jean Piaget. Neste contexto as características e adequabilidade destes ambientes são discutidas em relação aos princípios básicos da teoria, que também são apresentados.
\end{abstract}

Palavras-Chave: aprendizagem cooperativa, construtivismo, ACAC, epistemologia.

Abstract: A Computer Supported Collaborative Learning (CSCL) environment can be a very important element in the learning process in any area, as long as the epistemological approach that guided its creation and development is harmonic with the teacher's pedagogical practice. Thus, the effectiveness of these environments can only be assessed under the light of a learning paradigm. In this work, $\mathrm{CSCL}$ environments were evaluated through the view of a socio-constructivist approach of Jean Piaget"s Genetic Epistemology. In this context, the characteristics and adequacy of these environments is discussed in relation to the theory basic principles, which are also presented

Key-words: cooperative learning, constructivism, CSCL, epistemology.

\section{Introdução}

As características da sociedade nas últimas décadas tem tornado o homem cada vez mais competitivo, especializado, individualista e apegado a valores materiais. Na contra-corrente destas tendências, filósofos e pensadores contemporâneos, entre os quais podemos citar Edgar Morin e Humberto Maturana pregam uma visão mais holística das situações. Estas idéias baseiam-se na crença de que não é possivel entender-se o mundo complexo, globalizado e interconectado de hoje através de uma análise fragmentada da realidade.

Assim, o Professor Michael Gibtion (THE ECONOMIST, 1997), secretário geral da Associação das Universidades do Commonwealth, vê os maiores avanços científicos hoje em dia como conseqüência não da colocação de um tijolo sobre o outro dentro de uma disciplina única, mas da resolução de problemas complexos que trespassam diversas disciplinas. Para ele, ou as universidades se modificam, adaptando-se às mudanças, ou elas serão empurradas para a margem da ciência. Nesta mesma linha, Edgar Morin (2000) prega a necessidade de uma "reforma do pensamento", a qual "permitiria o pleno emprego da inteligência para responder a esses desafios e permitiria a ligação de duas culturas dissociadas. Trata-se de uma reforma não programática, mas paradigmática, concernente a nossa aptidão para organizar o pensamento" (p.20).

Engenheiro químico, Mestre em Ciência e Gerenciamento dos Alimentos (University of London), Doutor em Informática na Educação (UFRGS), professor do Instituto de Ciência e Tecnologia de Alimentos (UFRGS), prometo@ terra.com.br, penta.ufrgs.br/ julio

* Engenheira química, Mestre em Ciência da Computação (PUC/RS), Doutoranda em Informática na Educação (UFRGS), professora da UERGS, mara @ pgie.ufrgs.br, www.pgie.ufrgs.br/ mara

*** Psicólogo Mestre e Doutor em Educação (UFRGS), professor do Pós-Graduação em Informática na Educação (UFRGS) e da Faculdade de Educação (UFRGS), franco@edu.ufrgs.br, http://www.pgie.ufrgs.br/-franco/sergio/. 
Nesta mesma linha, é cada vez mais comum falar-se em Ecologia Cognitiva, sinalizando a percepção de que os conhecimentos só tem significado quando inseridos em um contexto, e a intensa interrelação entre o desenvolvimento cognitivo e o social. Como diz Pierre Lévy (1993):

\begin{abstract}
"a inteligência ou cognição sāo o resultado de redes complexas onde interagem um grande número de atores humanos, biológicos e técnicos. Não sou "eu" que sou inteligente, mas "eu" com o grupo humano do qual sou membro, com minha língua, com toda uma herança de métodos e tecnologias intelectuais (dentre as quais o uso da escrita)(p.135)."
\end{abstract}

Os resultados das pesquisa de Doise \& Mugni (apud DILLEMBOURG, 1995), mostraram que, em certas condições, o trabalho de pares era melhor do que dos indivíduos. Partindo-se destas considerações, tem sido comprovado por diversos pesquisadores que a aprendizagem acontece no interior de cada indivíduo, mas que pode ser incentivada pelas trocas sociais, isto é, atribui às interações sociais ou à cultura um papel preponderante no desenvolvimento cognitivo do sujeito. Este é o princípio básico da Aprendizagem Cooperativa. Somando-se a isto os avanços ocorridos no campo da informática, mais especificamente em relação as ferramentas de comunicação e interação, chega-se à Aprendizagem Cooperativa Apoiada por Computadores. Como produto final deste campo de pesquisa tem-se os Ambientes de Aprendizagem Cooperativa Apoiada por Computador (ACAC), onde apenas sob este título já existem diversas fontes de pesquisa como apontado por Dillembourg (1999) na introdução de um livro sobre Aprendizagem Cooperativa.

Em nosso ponto de vista, para que a utilização destas novas tecnologias em um contexto educacional seja realmente efetiva, é fundamental que exista uma profunda ligação entre as bases epistemológicas da conduta educacional do professor e da abordagem pedagógica adotada no projeto do ambiente. Sem esta ligação, estaremos simplesmente fazendo uma pseudo-modernização de uma prática educativa sem significado. Neste artigo pretendemos discutir uma abordagem social-construtivista de aprendizagem, criada a partir da Epistemologia Genética de Jean Piaget, e analisar os recursos proporcionados por alguns ambientes de ACAC sob a luz deste paradigma.

\title{
2. Aprendizagem Cooperativa Apoiada por Computador (ACAC)
}

\subsection{Cooperação ou colaboração}

Como já apontado por outros autores (DILLEMBOURG, 1995; PANITZ, 2001) existe uma polêmica sobre a utilização dos termos aprendizagem cooperativa e aprendizagem colaborativa. Na lingua inglesa, os principais pesquisadores têm utilizado o equivalente a aprendizagem colaborativa, deixando cooperativa para a área do trabalho. No Brasil, esta polêmica também existe (NITZKE et al., 1999) estando, porém mais relacionada à questão epistemológica. Nos termos deste trabalho seguiremos a terminologia "aprendizagem cooperativa" em virtude da forte base piagetiana de nossos trabalhos, onde o construto "cooperação" tem um significado específico.

Independentemente do termo utilizado, o que realmente interessa neste campo de estudo é a realização de um trabalho em conjunto, não a simples aglutinação de trabalhos individuais. Para Piaget (1998), esta definição é fundamental pois pressupõe que o sujeito encontre-se em um estágio de desenvolvimento no qual ele seja capaz de realizar operações de reciprocidade, sem as quais ele não é capaz de descentrar-se. Enquanto os sujeitos não ultrapassarem seu período de pensamento egocêntrico, estaremos "em presença de dois indivíduos, incapazes de se compreenderem, na medida em que cada um tem o hábito de pensar e de falar para si mesmo" (p.73), tornando impossível a cooperação.

É importante salientar-se, que não importa qual o termo utilizado, o que se pretende é o mesmo significado atribuido por Roschelle (apud DILLEMBOURG, 1995) à colaboração: "...uma atividade coordenada e síncrona que é o resultado de uma tentativa contínua de construir e manter uma concepção compartilhada de um problema". Com esta definição fica explícita a necessidade de algo a ser realizado em comum, para o que será necessária uma intensa negociação, uma vez que a solução deverá ser compartilhada e não "colada". 


\subsection{0 que significa aprendizagem?}

Como apresentado na Introdução, é fundamental que se tenha uma visão muito clara do significado de "aprendizagem". Os resultados apresentados por Lipponen (1999) no CSCL99 sobre a introdução de CSCL em escolas primárias e secundárias na Finlândia indicaram que os principais desafios encontrados são aqueles relacionados com as práticas pedagógicas adotadas, que por sua vez, estão diretamente relacionadas com a visão de aprendizagem vigente.

Por muitos séculos tem-se acreditado que o conhecimento é como algo fluido, que possa ser repassado de um professor de "magno saber" para um aluno que nada sabe. Em outras palavras, acreditase que é possível um professor ensinar (da origem latina "insignare", que significa a transmissão do conhecimento, de informação ou de esclarecimentos úteis ou indispensáveis à educação e à instrução) um aluno, sendo esta a base epistemológica da educação, em todos os níveis, na maioria das instituições atuais.

Pfister et al. (1999) assume uma posição muito comum entre os pesquisadores de computação, ao dizer, para simplificar, que o conhecimento pode ser descrito como uma coleção de fatos; sendo que o termo é utilizado de forma completamente genérica, incluindo unidades cognitivas tais como proposiçōes, regras, produções, etc. Os estudos científicos de Jean Piaget, realizados no século passado, sobre a maneira pela qual o ser humano adquire conhecimento, apontam para outra direção.

Em sua Epistemologia Genética (1990), Piaget considera que o desenvolvimento cognitivo ocorre como conseqüência de uma interação entre o sujeito e o objeto fruto de seu interesse. $O$ cérebro humano funciona baseado em esquemas de significação, os quais estão em permanente adaptação através de processos contínuos e simultâneos de assimilação (os esquemas do sujeito modificam-se para incorporar os elementos do objeto) e acomodação (os elementos do objeto são modificados pela ação do sujeito). Assim, para o desenvolvimento cognitivo é necessário que ocorra um desequilíbrio neste processo, o que ocasionará o aparecimento de novos esquemas a partir daqueles já existentes, desencadeando uma espiral crescente ligada a inúmeras outras, através das teias de significação individuais. Neste contexto, a aprendizagem surge como um processo que ocorre na relação entre quem ensina e quem aprende e mesmo entre os que aprendem, mas a construção será individual, ou seja, cada um aprenderá à sua maneira.

Há um conceito de Piaget ainda pouco explorado na literatura, mas que ajuda a compreender de forma bem mais completa o processo de aquisição de conhecimentos, e, por extensão, de aprendizagem. Trata-se da noção de abstração reflexionante (PIAGET, 1995). A teoria da abstração demonstra como se pode construir novidades no pensamento. Através dela, Piaget pôde demonstrar de forma mais completa, porque não se ensina de forma determinista um conhecimento novo, e porque esse conhecimento não é fruto nem da maturação do aprendiz nem da imposição do professor ou do material didático, ou mesmo da pura experiência empírica.

Ao afirmar que todo conhecimento novo é construído, porque se retira essa novidade das coordenações das ações ou das coordenações das coordenações de ações, e não diretamente dos observáveis (objetos e ações), Piaget está mostrando que não basta apresentar o conteúdo para que o aluno aprenda. É preciso criar situações para que esse aluno estabeleça relações. Para que estabeleça relações entre relações, que faça construções renovadas e reinvente as noções que se pretende que ele aprenda. Só assim se alcança a compreensão de um conhecimento.

Traduzindo-se estes conceitos para o plano pedagógico, percebe-se que a figura de um professor que "ensina" um aluno torna-se incoerente e um novo papel deve ser designado ao professor. Nesta visão, o professor passará a auxiliar, incentivar e proporcionar ao aluno a "construção" de seu conhecimento, através de um processo participativo, razão pela qual a aplicação da teoria piagetiana à educação leva o nome de Construtivismo.

Em função de sua base construtivista, a expressão ensino-aprendizagem não será utilizada neste trabalho, mas será substituída por "promoção da aprendizagem", como vista pela teoria de Piaget, como principal função da educação. 


\subsection{A abordagem sócio-construtivista da Aprendizagem Cooperativa}

$\mathrm{Na}$ sociedade em que vivemos, o peso da influência do social, ou da cultura no desenvolvimento pessoal é cada vez mais considerado, como pode ser observado nos trabalhos dos pensadores atuais, entre os quais podem ser citados Pierre Lévy (1993), Edgar Morin (2000) e Humberto Maturana (2001).

Piaget, que tem sido criticado por não ter privilegiado o social no desenvolvimento cognitivo, também considerava a importância das interações. Para ele, "é precisamente a permuta constante de pensamentos com os outros que nos permite descentrar e assegurar a possibilidade de coordenar interiormente as relações que emanam de pontos de vista distintos". Em seu livro Estudos Sociológicos (1973), Piaget demonstra o quanto os processos sociais atuam juntamente com os psicológicos no desenvolvimento cognitivo. Permanece o conceito básico da ação do sujeito sobre o objeto, mas explicitando que não ocorre com um "eu" apenas, mas com um "nós" e que as ações são, de fato, interações, ou seja, "condutas se modificando umas às outras, ..., ou formas de cooperação, quer dizer operações efetuadas em comum ou em correspondência recíproca" (p. 22). Talvez seja importante ressaltar que o entendimento dessa interação em Piaget é mais do que simplesmente uma troca entre pessoas ou entre o sujeito e seu objeto de conhecimento. A interação significa exatamente a simultaneidade entre os agentes, e que, portanto, o conhecimento acontece no encontro e não em apenas um dos participantes. Sujeito e objeto, assim como aluno e professor ou aluno e colega, não são uma oposição binária, mas uma díade dialética e por isso dinâmica, que gera modificações em ambos os participantes, já que um constitui o outro pela própria oposição que Ihes caracteriza. (FRANCO, 1999).

Prosseguindo com os trabalhos de Piaget, Perret-Clermont (1978) concentrou-se na influência das interações sociais no desenvolvimento cognitivo, salientando a importância do conflito sociocognitivo em uma abordagem interacionista e construtivista. Para ela, "a interação social não oferece unicamente uma espécie de "alimento intelectual" para assimilar, mas também, e sobretudo, suscita uma atividade de adaptação que é, ela sim, criadora de inovação" (p.296).

Segundo Dillembourg et al. (1995), esta perspectiva é a base para uma abordagem socioconstrutivista da aprendizagem cooperativa. Uma das diferenças entre esta abordagem e as outras duas (sócio-cultural e cognição compartilhada) é ser baseada em um processo dinâmico e dialético. Isto significa que mesmo que dois alunos com o mesmo nivel de desenvolvimento cognitivo poderão usufruir de sua interação, pois cada um estará participando de acordo com sua perspectiva, o que pode favorecer uma situação de conflito, levando à aprendizagem.

\section{Ambientes de ACAC}

As seções anteriores tiveram a intenção de sublinhar a importância da opção por uma determinada epistemologia na criação ou escolha de uma determinada metodologia ou ambiente de trabalho para a educação. A principal preocupação dos professores é com a quantidade de material a ser repassado a seus alunos, com algumas tentativas de aperfeiçoamento do padrão estético das informações transmitidas. As tecnologias da informática servem perfeitamente para esta finalidade, com sua capacidade de acrescentar cores, movimento e sons ao repasse de informações. Em nosso ponto de vista, no entanto, esta representa uma grande sub-utilização das potencialidades oferecidas para o aprimoramento da aprendizagem.

Justamente pensando numa utilização inteligente das tecnologias de computação têm sido desenvolvidos os ambientes de ACAC. Estes ambientes usufruem não só da armazenagem de informações, mas principalmente, da comunicação e interação entre pessoas a uma velocidade, eficiência e custo não atingidos pelos outros meios existentes, para promover a aprendizagem cooperativa. Neste contexto, os ambientes ACAC caracterizar-se-iam por uma abordagem social-construtivista, cujos pressupostos básicos podem ser sumarizados pela importância da contribuição do grupo na construção individual do conhecimento pelo sujeito.

Os ambientes de ACAC têm sido mais freqüentemente empregados para suporte à educação a distância (EAD), mas a utilização para o ensino presencial também está prevista. A Figura 1 apresenta uma ilustração baseada no modelo para o processo de aprendizagem proposto por Souza (2000) para ambientes com uma abordagem construtivista de aprendizagem. 


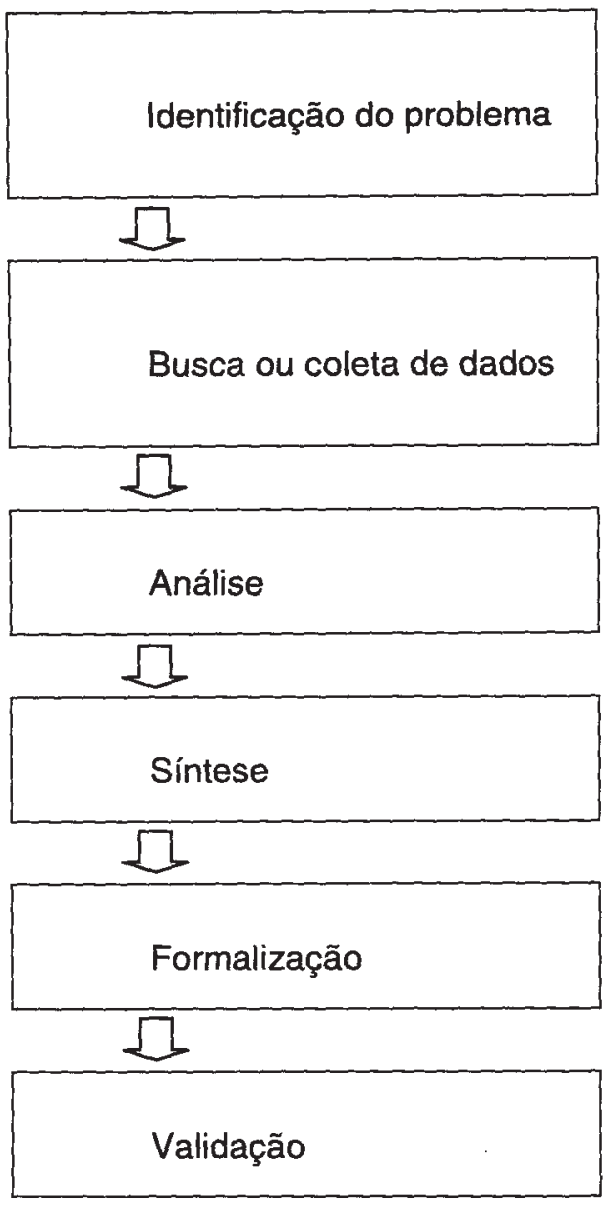

Exposição do problema ou desafio

Eliminação de dúvidas

Confirmação da compreensão

Consulta e busca de materiais

Contacto com especialistas

Manipulação dos dados

Filtragem das informações

Tomada de conclusões

Construção da síntese

Discussão interna dos resultados

Disponibilização do trabalho

Discussão dos resultados

Realização de experimentos

Avaliação final

Figura 1 - Modelo para o processo de aprendizagem (Segundo Souza, 2000)

As ferramentas e recursos mais utilizados são editores de textos e hipertextos, fóruns de discussão, correio eletrônico, quadros compartilhados (whiteboards), aplicativos de vídeo, etc, e variam em cada ambiente, para atingirem-se as finalidades propostas, e a adequação de cada ambiente. Partindo-se deste modelo será realizada uma análise de dois ambientes de ACAC,enfocando-se a questão epistemológica da aprendizagem.

\subsection{Descrição dos ambientes}

Visando apoiar a nossa análise, descrevemos a seguir dois ambientes desenvolvidos para apoio à Educação a Distância e que, em nossa opiniäo, apresentam características bem diferenciadas e servem para avaliar a adequação do ambiente à proposta pedagógica.

\section{Aulanet (http://www.eduweb.com.br)}

O AulaNet é um ambiente de aprendizagem cooperativo baseado na Web, cujo projeto iniciou em 1997. Desenvolvido no Laboratório de Engenharia de Software (LES) do Departamento de Informática da Pontifícia Universidade Católica do Rio de Janeiro (PUC-Rio), tem como objetivo a criação e assistência de cursos a distância.

Os objetivos estabelecidos pela equipe de desenvolvimento do AulaNet são: promover a adoção da Web como um ambiente educacional; contribuir com mudanças pedagógicas, dando suporte à recriação; encorajar a evolução do conhecimento e criar comunidades de conhecimento (Lucena et alii, 1998). 


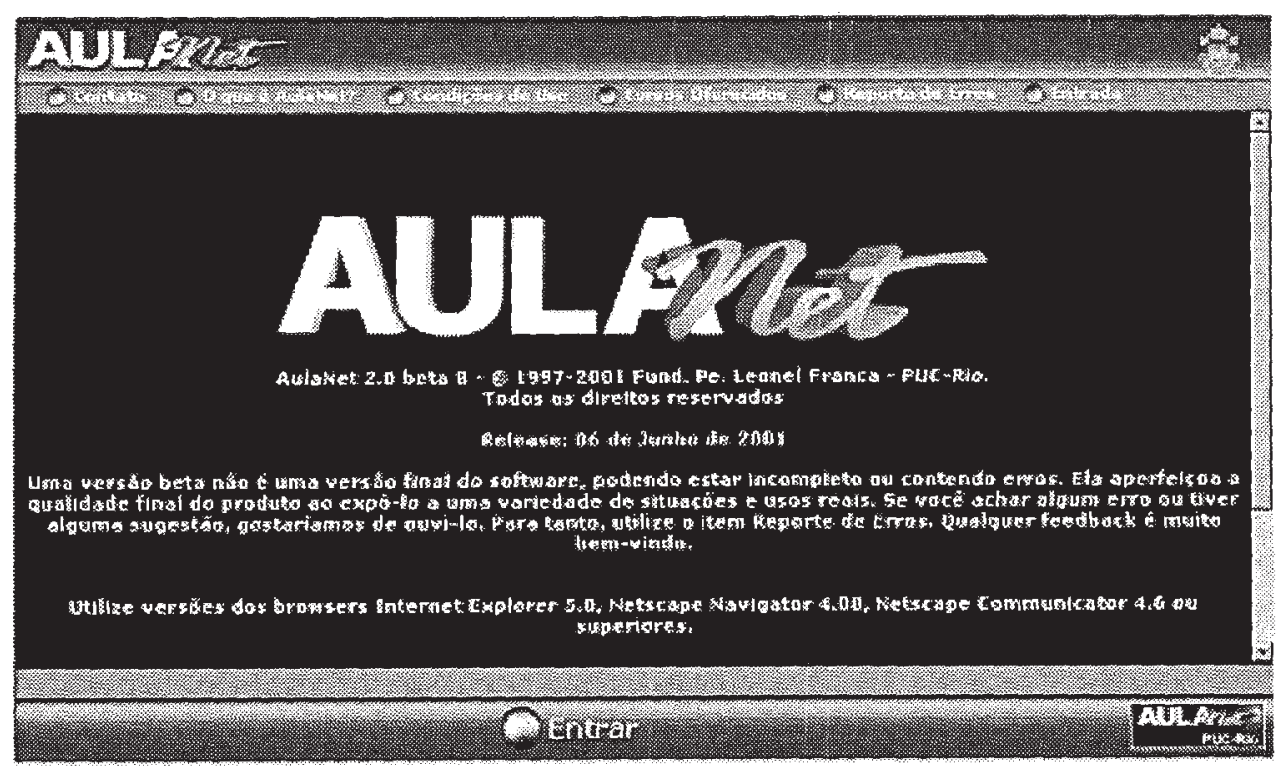

Figura 2 - Ambiente AulaNet- tela inicial (versão 2.0)

O foco do desenvolvimento é o apoio ao professor na criação de seus cursos. Com o AulaNet, o professor não precisa conhecer nenhuma linguagem de programação para a Internet para criar, alterar ou ministrar cursos a distância, pois o ambiente promove a separação entre o conteúdo e a navegação. Um conjunto de mecanismos de comunicação, coordenação e cooperação são oferecidos para que o professor possa customizar seu curso de acordo com os objetivos do processo de aprendizado que devem ser alcançados.

O ambiente baseia-se em uma abordagem cooperativa, adotando o enfoque de groupware e fugindo das metáforas adotadas pela maioria dos ambientes atuais, que simulam salas de aula, bibliotecas, quadro-negro, etc. (LUCENA et alii, 2000). Neste enfoque, a cooperação significa a possibilidade de contribuir para o trabalho em grupo, não necessariamente através da interação entre os constituintes do mesmo.

Para Lucena et alii (2000), no AulaNet, o conceito de cooperação deve ser entendido como a preparação do material pelo professor e, de um ponto de vista construtivista, a criação de um espaço para a contribuição de outros participantes (outros professores e os próprios aprendizes). Entre estes mecanismos existem ferramentas para a transferência de materiais e indicação de professores e aprendizes co-autores.

Os mecanismos de comunicação fornecem suporte à troca ou o envio de informação entre professores e aprendizes. Estes mecanismos incluem correio eletrônico, lista de discussão, conferência assíncrona textual (newsgroup) e conferência síncrona textual (chat). Os mecanismos de coordenação fornecem recursos para a organização do trabalho em grupo: agenda (gerência de calendário) e avaliação de aprendizado. Os mecanismos de cooperação fornecem os meios para a promover o aprendizado, a resolução de problemas e a realização de tarefas em grupo, isto é, os meios para o compartilhamento de idéias e informação.

\section{Ambiente TelEduc (http://hera.nied.unicamp.br/teleduc)}

O TelEduc é um ambiente para realização de cursos a distância através da Internet. Desenvolvido pelo Núcleo de Informática Aplicada à Educação do Instituto de Computação da UNICAMP sob a orientação da Profa. Dra. Heloísa Vieira da Rocha, o projeto teve originalmente por objetivo apoiar a formação de professores a partir de um método construído com base na análise das várias experiências presenciais realizadas pelos profissionais daquele núcleo. 


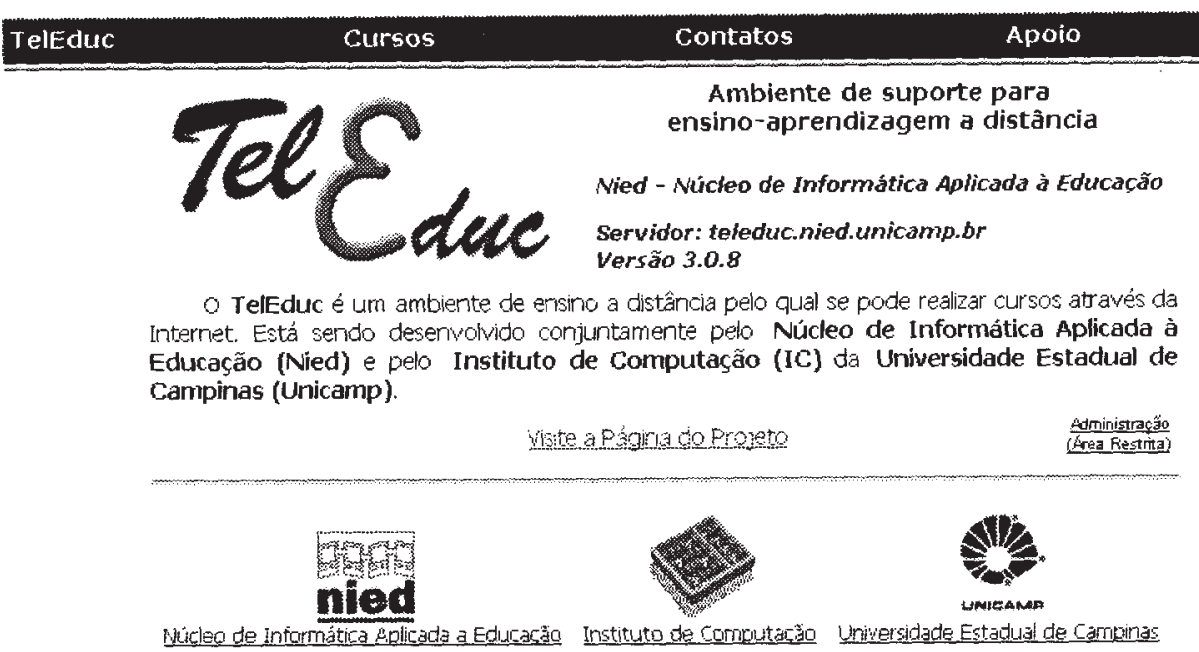

Figura 3 - Ambiente TelEduc - tela de abertura

Os usuários deste ambiente podem assumir diversos papéis:

- aluno: aquele que participa de um curso e tem autorização somente para publicar material em algumas das ferramentas disponíveis;

- formador: esta é a denominação utilizada pelo TelEduc para designar o professor (ou tutor) responsável pelo curso. O formador é o responsável pela organização e publicação de todo o material do curso;

- coordenador: é o responsável pela administração do curso, principalmente gerenciando as inscriçōes.

- administrador: responsável pelo ambiente TelEduc, é a pessoa que tem autorização para criar novos cursos, entre outras atribuições.

O conjunto total de funcionalidades oferecidas pelo TelEduc pode ser reunido em quatro grandes grupos: ferramentas de coordenação, ferramentas de comunicação, ferramentas para divulgação e ferramentas de administração.

No grupo das ferramentas de coordenação, estão incluídas as ferramentas que, de alguma forma, organizam e subsidiam as ações de um curso. Neste conjunto Estrutura do ambiente, Dinâmica do curso, Agenda, Atividades, Material de Apoio, Leituras, Perguntas Freqüentes e Parada Obrigatória.

No conjunto de ferramentas de comunicação tanto síncrona quanto assíncrona estão: Mural, Fóruns de discussão, Bate-papo e Correio. Todas são ferramentas internas ao sistema, ou seja, o usuário deve estar conectado ao TelEduc para ter acesso a estes recursos.

O terceiro grupo envolve os espaços destinados à publicação dos trabalhos e produções dos alunos e são: Diário de Bordo e Portfólio (Individual e do Grupo). O recurso Grupos permite que os alunos reúnamse em grupos de trabalho. A criação de um grupo automaticamente gera um portfólio para o grupo, onde todos os participantes podem publicar o material produzido pelo trabalho cooperativo.

O quarto e último grupos reúnem os recursos de administração do curso, onde se situam as ferramentas de apoio ao formador no gerenciamento da parte administrativa do curso, tais como Acessos (relatórios), Alterar senha, Administração e Suporte.

A página de entrada de um curso é dividida em duas partes. Na parte da esquerda estão disponibilizadas as ferramentas que serão utilizadas durante o curso e, na parte da direita, é apresentado o conteúdo correspondente à ferramenta selecionada (Fig. 4). Cada curso no TelEduc pode utilizar um subconjunto de qualquer das ferramentas oferecidas pelo ambiente. 


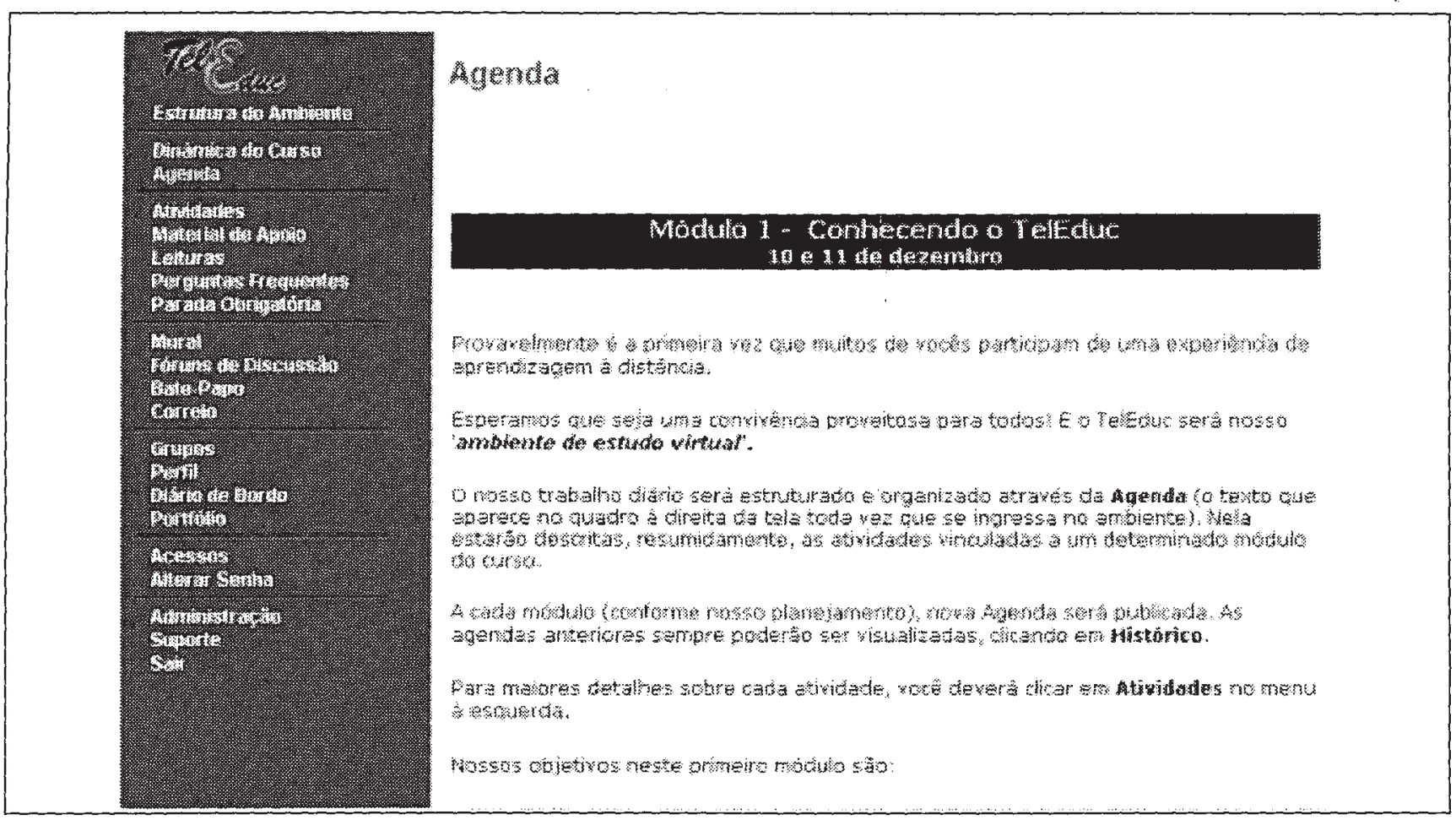

Figura 4 - Página de entrada de um curso

\subsection{Análise dos ambientes}

Os dois ambientes apresentados têm sido utilizados em cursos promovidos pela UFRGS e constituem duas categorias bem distintas, considerando suas caracteristicas e recursos oferecidos.

O Aulanet poderia ser caracterizado como ambiente para learningware, termo que combina as características de courseware com as várias formas de interação (interação entre aprendizes e a interação aprendiz/instrutor). O principal enfoque deste ambiente é permitir uma interação entre os participantes na discussão de materiais previamente preparados pelo professor. $O$ ambiente é de uso fácil tanto por parte do professor, apoiado por uma série de recursos na criação e disponibilização de um novo curso, quanto por parte do aluno, que pode acessar todas as ferramentas do curso por um menu sempre visível (denominado de "controle remoto"). No entanto, as facilidades oferecidas ao professor privilegiam a exposição de materiais de apoio e o repasse de informações.

Esta postura, no entanto, não privilegia o crescimento do conhecimento, sob uma ótica construtivista. De acordo com Piaget, o fato de o aluno ter acesso fácil ao material disponibilizado pelo professor não garante a aprendizagem. Para que isto ocorra, é necessário que o aluno faça relações entre relações, o que pode ser instigado ou auxiliado pelo professor, mas jamais construído pelo professor na mente do aluno. Ele deverá realizar sua própria reinvenção das noções em discussão.

No Aulanet, a participação dos alunos ocorre quase que somente através da discussão em listas ou pela realização de trabalhos, exercícios e provas. Estes não são compartilhados com os colegas, como seria esperado em uma aprendizagem cooperativa, mas servem principalmente como recurso de avaliação, centrados na forma tradicional do certo $x$ errado. Esta conduta fica explicitada pela própria descrição dos mecanismos de cooperação, que assim a entendem como ferramentas de auxílio ao professor na elaboração de materiais a serem apresentados. A participação de alunos na elaboração destes materiais está prevista, mas através da permissão do professor, em caráter extraordinário e não como metodologia de participação, pois não está existe nenhum espaço para publicação dos trabalhos dos alunos

Avaliando-se este ambiente do ponto de vista do modelo apresentado (Fig.1), depreende-se que uma etapa muito importante nos princípios da aprendizagem cooperativa, a de formalização, fica prejudicada. É nesta etapa que os alunos disponibilizam o resultado de sua busca, análise e síntese para apreciação e discussão com seus colegas, podendo então usufruir de todos os benefícios provocados pelos conflitos sócio cognitivos, que podem promover a aprendizagem. Ainda, em virtude das poucas possibilidades para a realização de um trabalho conjunto, este ambiente seria caracterizado não como um 
cooperativo, mas sim como colaborativo, no sentido que dificilmente os alunos poderiam compartilhar a construção de um trabalho em conjunto, mas sim juntar peças que poderiam ser criadas separadamente e simplesmente encaixadas para constituir o todo.

O ambiente TelEduc possui uma estrutura mais aberta, que também poderia ser utilizada para o instrucionismo, porém possibilita um processo de aprendizagem mais condizente com os processos previstos na teoria construtivista. Isto se deve ao fato de que o seu desenvolvimento baseou-se no conceito de formação centrada na construção contextualizada do conhecimento, que começou a ser desenvolvido no NIED em 1997 (ROCHA, 2002, p. 200).

A grande diferença entre os dois ambientes encontra-se na forma como a aprendizagem é colocada para ao aluno. No primeiro ambiente, o ponto de partida são textos, apresentações ou bibliografias disponibilizadas pelo professor aos alunos. No segundo, a base do conhecimento é explicitada através de atividades a serem desenvolvidas pelos alunos e compartilhados com o grupo através da publicação em Portfólios (individuais ou grupais). Neste contexto todo o ambiente foi projetado para dar suporte a este tipo de trabalho e não à transmissão de conteúdos pelo professor. Assim, com uma aprendizagem baseada em projetos (FAGUNDES, 1999), os alunos deverão percorrer todas as fases previstas no modelo apresentado na Fig.1.

Neste ambiente, a partir das atividades e desafios propostos pelo professor, os alunos têm liberdade para conduzir sua construção da forma que desejarem e com os recursos que considerarem significativos para o processo. O importante é que, em qualquer das opções, a resposta obtida atenda a uma necessidade do aluno, pois, de acordo com Piaget (1998) uma aula só tem significado se isto ocorrer: "ela só responde a uma necessidade se os conhecimentos que traz corresponderem a realidades experimentadas e espontaneamente vividas pela própria criança."

As ferramentas de discussão disponíveis nos dois ambientes são praticamente as mesmas (correio, fórum de discussão, etc.), mas o tipo de comunicação e o tema das discussões é que diferencia a prática educacional em um ambiente ou outro. Enquanto no TelEduc, as discussões dão suporte às construções dos projetos individuais (ou grupais), no Aulanet, são específicas sobre temas propostos e direcionados pelo professor.

Ao contrário do AulaNet, que prioriza a construção individual, o TelEduc proporciona o recurso Grupos e respectivo Portfólio do grupo, como espaço de trabalho e publicação coletiva.

Apesar de terem sido projetados para a utilização em EAD, os ambiente podem e já foram utilizados como suporte a aulas presenciais ou mistas. Nestas experiências, percebe-se que os alunos ainda preferem muito mais o contato pessoal que recorrer aos fóruns e mensagens eletrônicas, demonstrando que, apesar de relativamente bem familiarizados com as novas tecnologias, elas ainda não os constituem. Mas esta visão está sendo modificada ao longo do tempo. Por terem um espaço de constante comunicação com o professor, o uso de ambientes como estes no apoio a cursos presenciais acaba mudando a relação espaço e tempo da aula presencial.

Nesta mesma linha, percebe-se, nos cursos essencialmente desenvolvidos a distância, o prazer proporcionado pela possibilidade de "ver" ou mesmo "ouvir" o seu interlocutor, daí a importância da inclusão de mais recursos para apoiar uma comunicação multimídia, como a videoconferência. $O$ apego aos antigos paradigmas também é percebido na introdução das práticas construtivistas, que obrigam o aluno a pensar e tomar decisões ao invés de copiar, memorizar e repetir informações. Os primeiros momentos são sempre traumáticos, porém após um período de adaptação o resultado tem sido sempre favorável.

\section{Consideraçōes finais}

A prática com diferentes ambientes de ACAC demonstrou a importância do planejamento prévio no sucesso da introdução de uma nova metodologia. O professor deve ter muito claro quais são os objetivos a serem atingidos com sua disciplina. Ele também deve definir qual a visão epistemológica sobre sua prática educativa, o que significa aprender e procurar conhecer as características e particularidades de seus alunos.

É importante salientar-se que neste trabalho não se buscou alguma avaliação de mérito ou qualidade, mas sim analisar a adequação de diferentes ambientes de ACAC a uma certa abordagem epistemológica de aprendizagem. Com isto esperamos ter demonstrado que, para julgar se um determinado 
ambiente de aprendizagem é bom ou ruim, é mais importante optar previamente por um determinado paradigma, pois somente assim poderemos responder se um determinado ambiente de ACAC constitui-se realmente um ambiente de aprendizagem.

Uma opção por um paradigma construtivista vai além de simplesmente proporcionar a participação dos alunos. Traz consigo o entendimento de que o aluno é um sujeito ativo não somente para escolher tarefas, mas para construir conhecimentos e apontar direções novas para o próprio curso em uma prática interativa e cooperativa, com seus colegas, com o(s) professor(es), com o ambiente informático e também com agentes externos. Disso se conclui que a adoção de um determinado ambiente pode trazer uma boa contribuição, principalmente quando o professor não deseja simplesmente transpor sua prática presencial para a prática a distância, nem apenas fazer concessões para o aluno "aprender sozinho", mas está disposto a redimensionar a própria significação do que é ensinar e aprender.

Tendo refletido acerca dessas considerações é que ele poderá optar por uma determinada abordagem pedagógica e escolher que tipo de ambiente melhor se adapta a suas intenções. Do contrário, o professor estará realizando uma "pseudo-modernização", que muito facilmente seduz pelo glamour a ela associado, mas que na realidade não provoca nenhum ganho cognitivo nem para ele, muito menos para seus alunos.

\section{Referências bibliográficas}

DILLEMBOURG, $P$. What do you mean by "collaborative learning"? In: P. Dillembourg. Collaborative learning: cognitive an computational approaches. Oxford: Elsevier, 1999. p. 1-19.

DILLEMBOURG, P.; BAKER, M.; BLAYE, A.; O'MALLEY, C. The evolution of research on collaborative learning. In: E. S. P.Reiman. Learning in humans and machines: towards an interdiciplinary learning science. Oxford: Elsevier, 1995. p. 189-211.

EDUWEB. Guia AulaNet 2001. Disponivel em <http://guiaaulanet.eduwe.com.br> Acesso em 04/05/2002.

FAGUNDES, L. D. C.; SATO, L.; MAÇADA, D. Aprendizes do futuro: as inovações começaram. Brasília: MEC , $1999,96 \mathrm{p}$.

FRANCO, S.R.K. Piaget e a dialética. In: BECKER, F e FRANCO, S.R.K. Revisitando Piaget. Porto Alegre: Mediação, 1999.

LEVY, P. As tecnologias da inteligência - O futuro do pensamento na era da informática. Rio de Janeiro: editora $34,1993,203 \mathrm{p}$.

LIPPONEN, L. The challenges for Computer Supported Collaborative Learning in elementary and secondary level: Finish Perspectives. In Computer Supported Collaborative Learning, 1999, Palo Alto, CA. Proceedings... Palo Alto: Lawrence Erlbaum Associates.

LOURENÇO, O. M. Além de Piaget? Sim, mas devagar. Coimbra: Livraria Almedina, 1994, 264 p.

LUCENA, C.J. et alii. AulaNet - An environment for the development and maintenance of courses on the Web. In: International Conference on Engineering Education. 1998, 1998, Rio de Janeiro. Proceedings ... Rio de janeiro:PUC-Rio, 1998b.

LUCENA, C.J et alii. AulaNet; Helping teachers to do their homework. Rio de Janeiro: Lab. de Engenharia de software, DI - PUC-Rio, 1998.

O AulaNet e as novas tecnologias de informação aplicadas à educação baseada na Web. In: Congresso Internacional de Educação a Distância, 4., 2000, Brasília. Proceedings... Brasilia: ABED, 2000.

MATURANA, H. A ontologia da realidade. Belo Horizonte Editora UFMG, 2001.

MORIN, E. A cabeça bem-feita. 2a ed. Rio de Janeiro: Bertrand Brasil , 2000, 128 p.

NITZKE, J. A.; CARNEIRO, M.L.; GELLER, M.; SANTAROSA, L. C. M. Avaliando aplicações para criação de ambientes de aprendizagem colaborativa. In: X Simpósio Brasileiro de Informática na Educação, 1999, 1999, Curitiba,. Anais ... p. 303-310.

PANITZ, T. Distinction between definitions of collaborative and cooperative learning. 1997. Disponivel em <http://forum.swarthmore.edu/epigone/cl/sayjelnol/jayktby7jnzb @ forum.swarthmore.edu>. Acesso em 21/02/2001.

PERRET-CLERMONT, A. N. Desenvolvimento da inteligência e interação social. Neuchatel: Instituto Piaget, 1978, $362 \mathrm{p}$. 
PFISTER, H-R. et alii. Negotiating about shared knowledge in a Cooperative Learning environment In Computer Supported Collaborative Learning, 1999, Palo Alto, CA. Proceedings... Palo Alto: Lawrence Erlbaum Associates

PIAGET, J. A explicação em sociologia. In: Estudos sociológicos. Rio de Janeiro: Companhia Editora Forense, 1973. p. $17-113$.

PIAGET, J. et alii. Abstração reflexionante. Porto Alegre: Artes Médicas, 1995.

PIAGET, J. O espírito de solidariedade na criança e a colaboração internacional. In: S. Parrat. Sobre a pedagogia textos inéditos. São Paulo: Casa do Psicólogo, 1998. p. 59-78.

ROCHA, H. O ambiente TelEduc para educação a distância baseada na web: Princípios, funcionalidades e perspectivas de desenvolvimento.", em MORAES, M. C. (Org.) Educação a distância: Fundamentos e práticas. Campinas, SP: UNICAMP/NIED, 2002, cap. 11, p. 197-212.

ROSNAY, J. D.; RODRIGUES, J. N. À procura do 5 paradigma para a gestão. Jorge Nascimento Rodrigues, 2000. Disponivel em <http://www.janelanaweb.com/digitais/rosnay.html>.Acesso em 23/01/2001.

SOUZA, R. S.; MENEZES, C. S. D.; SUZA, D. S. Inserção da Informática na Educação - Uma proposta baseada no processo de aprendizagem. In: XI Simpósio Brasileiro de Informática na Educação, 2000, Maceió. Anais do SBIE 2000 - As novas tecnologias da informação e comunicação na aprendizagem. Maceió: SBCp., 2000, p. 191198.

THE ECONOMIST. The knowledge factory - a survey of universities. The Economist, Londres, 04/10/1997, 22p. 